\title{
Synovial chondromatosis in a child's thumb: a case report and review of the literature
}

\author{
Hilton P. Gottschalk • Robert Newbury • \\ C. Doug Wallace
}

Published online: 17 November 2011

(C) American Association for Hand Surgery 2011

\section{Introduction}

Primary synovial chondromatosis consists of cartilaginous metaplasia of the synovium, which leads to the production of intra-articular and periarticular osteocartilaginous bodies $[8$, $12,18,19]$. The nomenclature has evolved with time to include chondromatosis of the joint capsule, diffuse enchondroma of the joint capsule, joint chondroma, synovial osteochondromatosis, and synovial chondromatosis $[8,9$, $16,18,20]$. Primary synovial chondromatosis most commonly occurs in young and middle-aged adults and is rarely found in children (youngest patient reported was 14 years old) $[12,19]$. The entity usually involves the synovium of large joints (knee, hip, elbow, and shoulder) $[3,8,15,16,18$, $19,26]$ but has been reported in the hand [2, 10-12, 20, 26]. To our knowledge, only two cases have been reported in the interphalangeal joint of the thumb $[13,14]$. We report on a 13-year-old female with primary synovial chondromatosis of the inter-phalangeal (IP) joint of her thumb.

\section{Case Report}

A 13-year-old right-hand dominant female presented with a 3 -year history of pain and progressive swelling over the

\author{
H. P. Gottschalk $(\bowtie) \cdot$ C. D. Wallace \\ Department of Pediatric Orthopaedic Surgery, Rady Children's \\ Hospital San Diego, \\ 3030 Children's Way, Suite 410, \\ San Diego, CA 92123, USA \\ e-mail: hpgottschalk@gmail.com \\ R. Newbury \\ Pathology Department, Rady Children's Hospital San Diego, \\ 3020 Children's Way, \\ San Diego, CA 92123-4282, USA
}

dorsum of her right thumb. She was initially seen by an adult hand surgeon for this mass, and because of her lack of symptoms at that time, she was observed. She gave no history of trauma and no other relevant medical history. On examination, several masses were located both on the dorsal and volar aspects of the thumb IP joint. The masses were focally tender and had a firm and nodular consistency. Range of motion was almost normal at the joint.

Radiographs of the hand at age 10 years showed mild soft tissue swelling with ossific densities adjacent to the distal aspect of the thumb proximal phalanx but no significant underlying bony erosion (Fig. 1). An MRI was obtained of the right hand which suggested intra-capsular involvement and likely benign entity (Fig. 2). Three years later, the radiographs revealed increased ossification of the densities (Fig. 3).

Because the patient had worsening pain and increase in the size of the masses, she underwent joint exploration and synovial biopsy. An "L-type" incision was used on the dorso-radial border of the thumb (Fig. 4). This allowed access to both dorsal and palmar aspects of the IP joint. Multiple firm, smooth, white nodules were found within a fibrous sac arising from the IP joint (Fig. 5). The synovium and loose bodies were excised and sent to pathology.

Histologic studies revealed well-circumscribed nodules of cartilage and bone. Several of the fragments were surfaced by a thin layer of synovium. The cartilage was of low-to-moderate cellularity and had unremarkable chondrocytes lying individually within the lacunae, indicative of primary synovial chondromatosis (Fig. 6).

Physical therapy for range of motion was initiated 3 weeks after surgery. Three months after surgery, she had painless range of motion with full extension, but lacking $10^{\circ}$ of full flexion. No recurrence was noted at 6 months post surgery. 
Fig. 1 a Anteroposterior (AP) and $\mathbf{b}$ lateral radiographs of a 10 -year-old female with mild soft tissue swelling and ossific density adjacent to the distal aspect of the thumb proximal phalanx
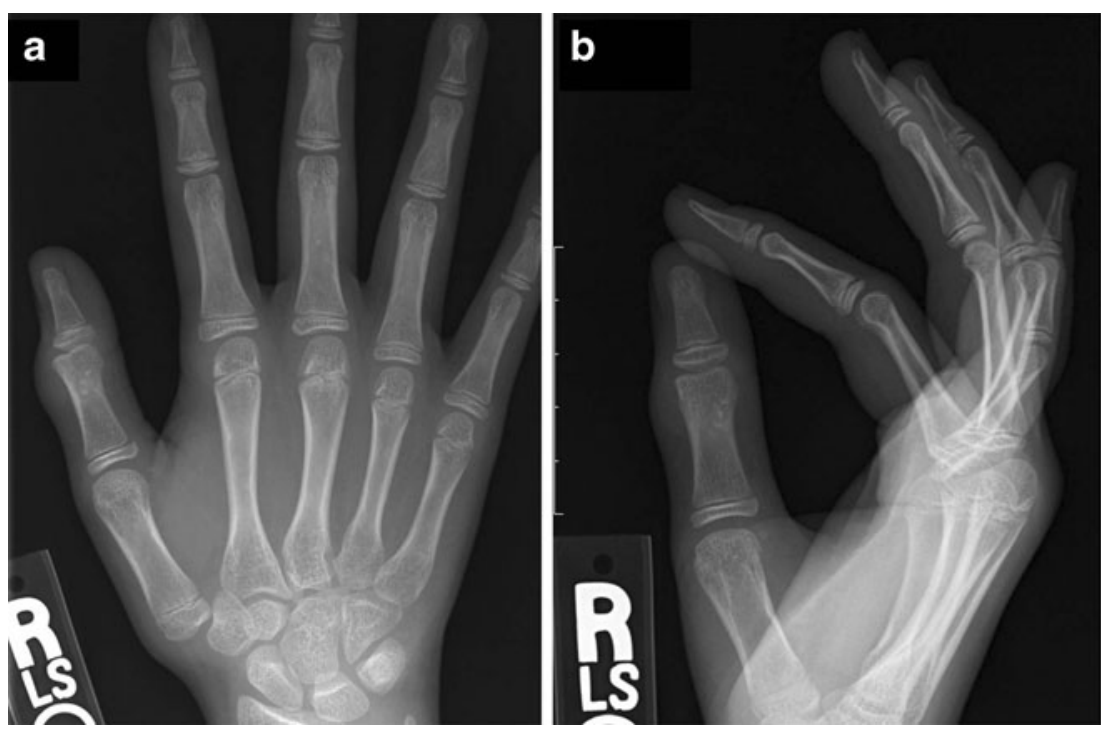

\section{Discussion}

Primary synovial chondromatosis is an uncommon condition characterized by benign metaplasia of synovial tissue into cartilaginous tissue $[2,8,10,18,20]$. The exact etiology of synovial chondromatosis remains unclear, but this primary form can originate from synovium or tenosynovium [4, 18, 20]. The tenosynovial form may be caused by trauma, in contrast to "intra-articular" chondromatosis, which has no such association [8, 12, 22].

These two entities are distinct from the more common secondary synovial chondromatosis, which occurs with the implantation of cartilage fragments into the tissue as a result of degenerative disease (osteoarthritis), neuropathic arthropathy, or trauma $[1,20,26]$.

Males are affected more than females, commonly ranging in age from the third to fifth decade of life $[3,12$, 13, 18]. Typically large joints are involved with the knee being the most common, followed by the hip and elbow [3, $8,15,16,18,19,26]$. This disease has been documented in the joints of the hand, specifically the metacarpophalangeal joint $[2,7,11,20,22,23,26]$ and interphalangeal joint [6, 10, 12-14, 25]. Only two of these cases involved the thumb interphalangeal joint $[13,14]$. When synovial chondroma-
Fig. 2 Magnetic resonance imaging of right thumb suggests intra-capsular involvement and loose bodies in the interphalangeal joint

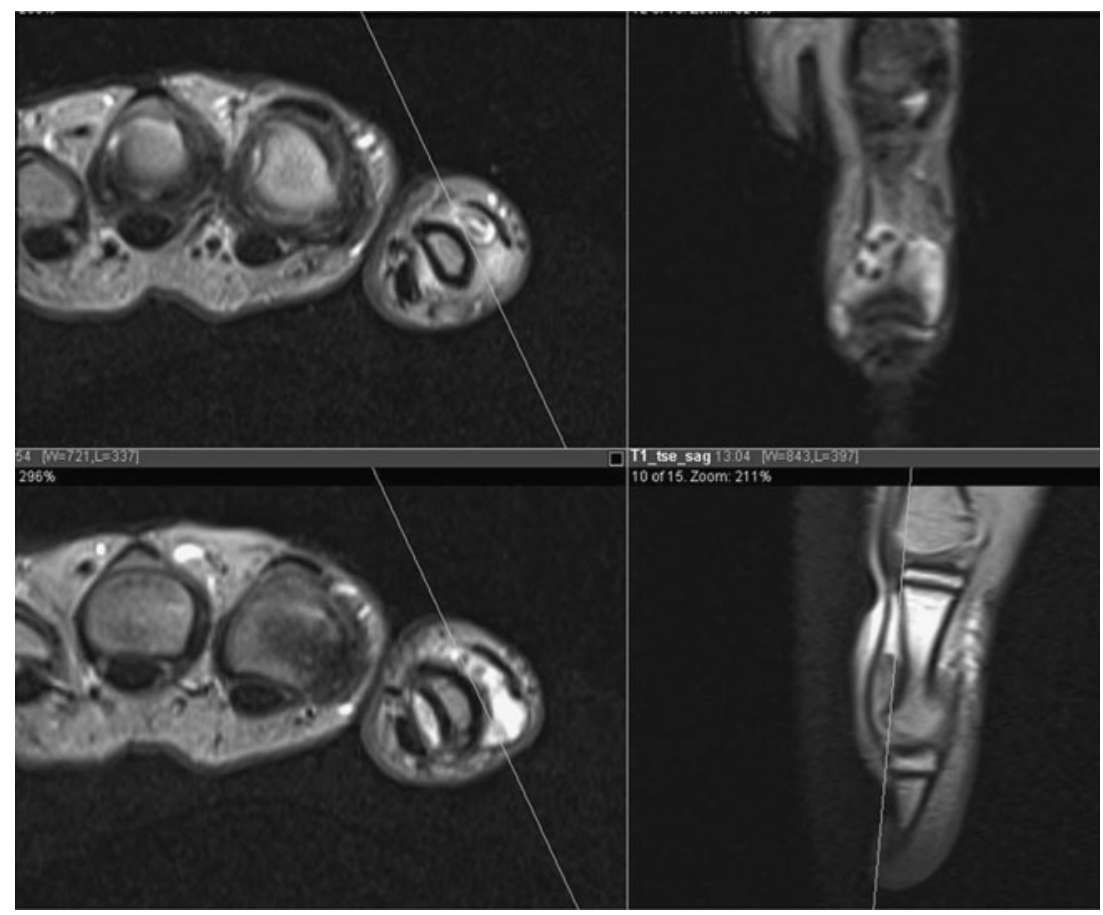


Fig. 3 AP and lateral radiographs of the same patient at 13 years of age with increased ossification of densities around the thumb proximal phalanx

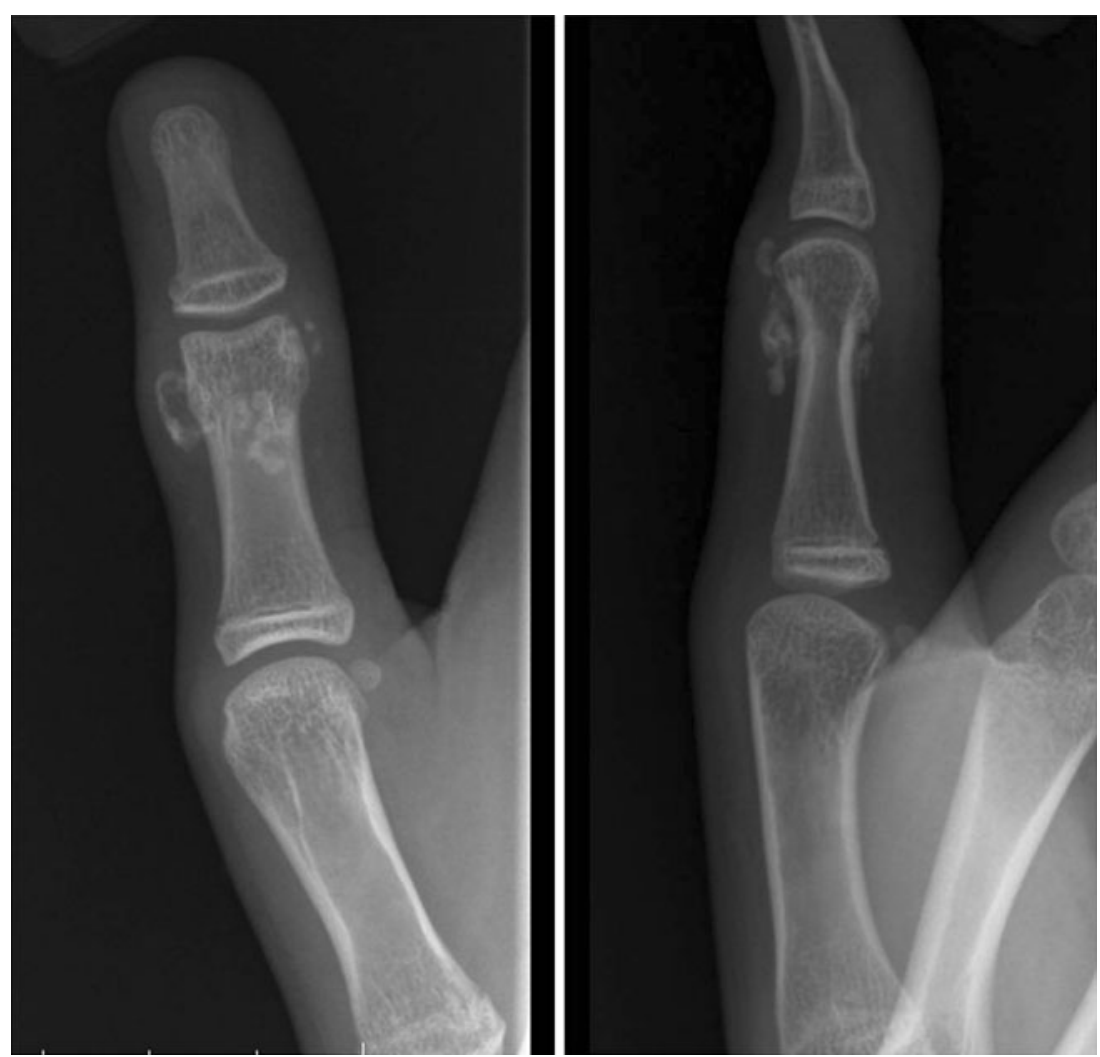

tosis occurs in the smaller joints, it has a predilection towards young women in contrast to that of the larger joints $[12,14]$.

The articular form of primary synovial chondromatosis can slowly progress, and patients will have symptoms present for months to years [8, 12]. Common presenting complaints include pain, swelling, and restriction of motion. Milgram described three separate phases: (1) active intrasynovial disease with no free loose bodies; (2)

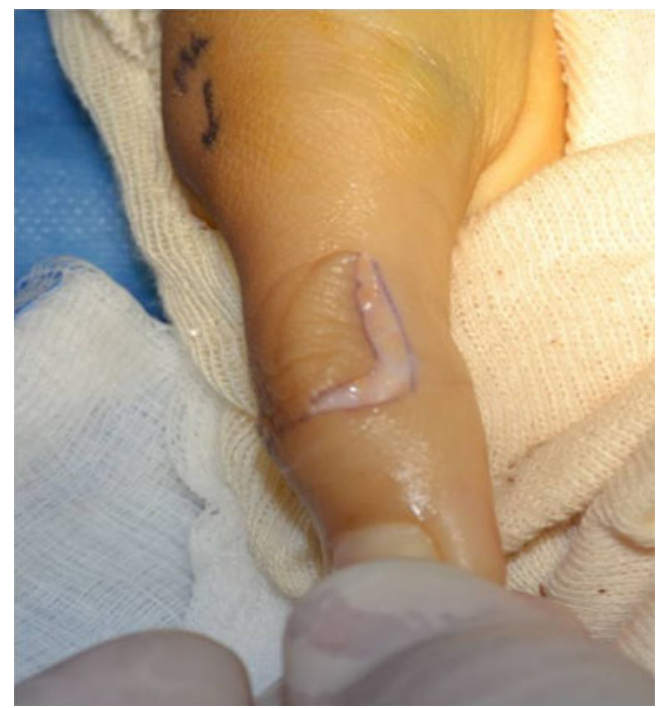

Fig. 4 "L-type" incision on the dorso-radial border of the right thumb
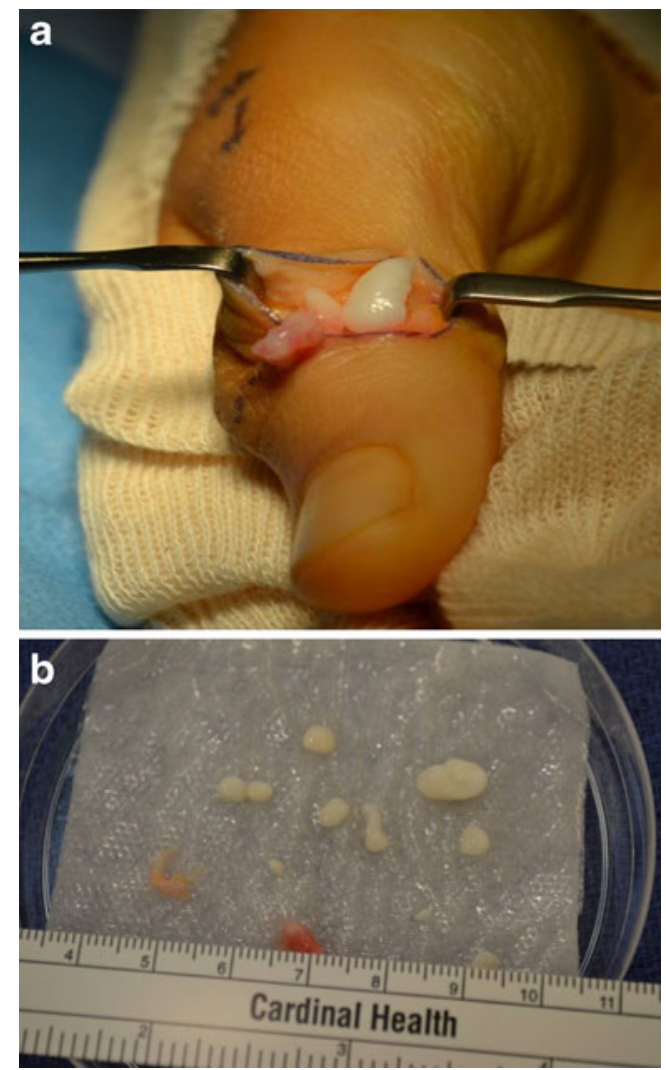

Fig. 5 a Smooth white nodule within a fibrous sac arising from the thumb interphalangeal joint. b Gross specimens retrieved from joint 

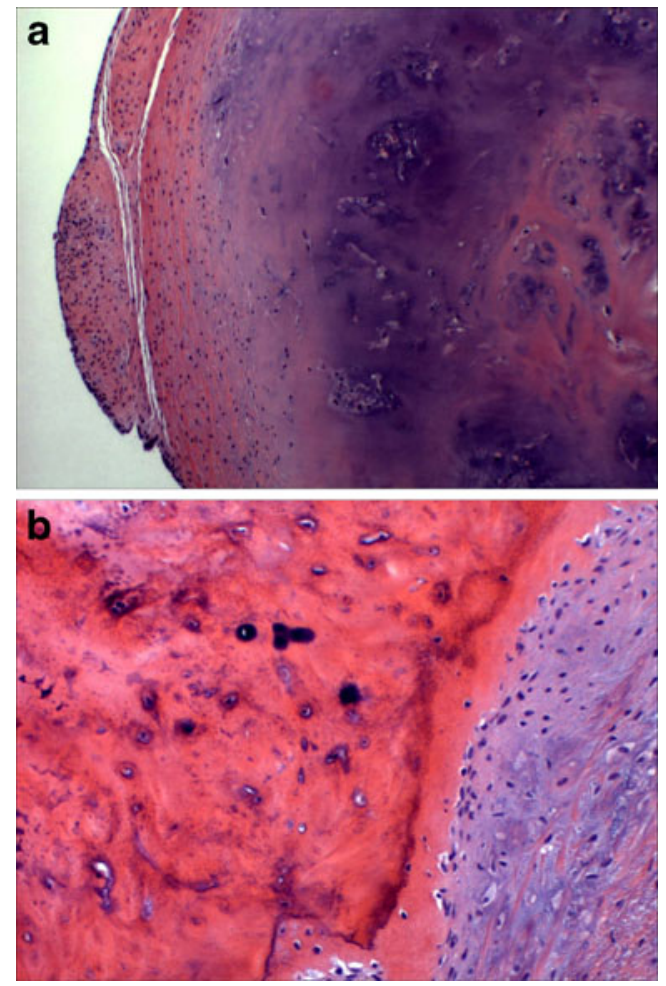

Fig. 6 a Nodule of cartilage surfaced by a thin layer of synovium (hematoxylin and eosin, original magnification $\times 100$ ). b Region of ossification within cartilaginous nodule (hematoxylin and eosin, original magnification $\times 200$ )

transitional lesions with osteochondral nodules in the synovial membrane and osteochondral bodies lying free within the joint cavity; and (3) multiple free osteochondral bodies, with now quiescent intrasynovial disease [16]. This patient likely had an initial presentation in the early phase (soft tissue swelling but no pain), and her symptoms worsened as she progressed to the transitional phase. The natural history of this condition is not well known. Milgram has described cases where some of the nodules have been resorbed spontaneously and not extruded into the joint [16]. However, if extra-capsular chondromatous lesions are present, then the lesions seem to behave more like a neoplasm versus a reactive process and surgical intervention is recommended.

Malignant transformation of this disease into synovial chondrosarcoma is exceedingly rare $[8,12,15,18]$, but Davis et al. have reported a risk of malignant change of 5\% (3 of 53 patients) [3]. As with other case reports on malignant transformation, all of these cases were in large joints $[3,5$, 17, 21, 24]. To our knowledge, no cases of malignant transformation have been seen in the finger joints.

Controversy remains regarding the extent of surgical treatment for primary synovial chondromatosis. The debate centers on preventing recurrence of the disease. Murphy et al. advocated removal of loose bodies with synovectomy.
They stated that the synovium "nourishes" the loose bodies which can remain viable and increase in size [18]. In contrast, Jeffreys recommended removal of loose bodies alone, with no recurrences reported [8]. The recurrence rate has been reported as high as $15 \%$; however, most of these cases involved large joints [3, 15]

Three cases of recurrence have been reported in the hand (two interphalangeal joints and one metacarpophalangeal joint) $[6,11,12]$. Other authors recommend that synovectomy should be done only if pain and swelling are the main symptoms. If mechanical symptoms predominate, then removal of loose bodies alone may be sufficient $[12,15]$. Since recurrence has been noted even after synovectomy (4 years later) [6, 12], we recommend that patients be counseled in this regard and offered periodic follow-ups to detect for recurrence.

Conflicts of Interest No pharmaceutical, industry, or outside support was used for this study. The authors report no conflicts of interest. No funding was received for this work from any of the following organizations: NIH, Wellcome Trust, Howard Hughes Medical Institute, and others.

\section{References}

1. Bui-Mansfield LT, Rohini D, Bagg M. Tenosynovial chondromatosis of the ring finger. Am J Roentgenol. 2005;184:1223-4.

2. Cremone JC, Wolff TW, Wolfort FG. Synovial chondromatosis of the hand. Plast Reconstr Surg. 1982;69:871-4.

3. Davis RI, Hamilton A, Biggart JD. Primary synovial chondromatosis. A clinico-pathologic review and assessment of malignant potential. Human Pathol. 1998;29:683-8.

4. Debenedetti MJ, Schwinn CP. Tenosynovial chondromatosis in the hand. J Bone Joint Surg. 1979;61A:898-903.

5. Hamilton A, Davis RI, Nixon JR. Synovial chondrosarcoma complicating synovial chondromatosis. Report of a case and review of the literature. J Bone Joint Surg. 1987;69A:1084-8.

6. Harvey FJ, Negrine J. Synovial chondromatosis in the distal interphalangeal joint. J Hand Surgery. 1990;15A:102-5.

7. Hettiaratchy SP, Nanchahal J. Synovial chondromatosis of the metacarpophalangeal joint. J Hand Surgery. 2002;27B(1):104-6.

8. Jeffreys TE. Synovial chondromatosis. J Bone Joint Surg Br. 1967;49B:530-4.

9. Jones HT. Loose body formation in synovial osteochondromatosis with special reference to the etiology and pathology. J Bone Joint Surg. 1924;6A:407-58.

10. Kettelkamp DB, Dolan J. Synovial chondromatosis of an interphalangeal joint of a finger. Report of a case. J Bone Joint Surg. 1966;48A:329-32.

11. Kriegs-Au G, Muller D. Recurrent chondromatosis of the metacarpophalangeal joint of the thumb - differential diagnosis and therapy [German]. Handchir Mikrochir Plast Chir. 2004;36:323-7.

12. Kumar A, Thomas AP. Recurrent synovial chondromatosis of the index finger - case report and literature review. Hand Surgery. 2000;5:181-3.

13. Lewis MM, Marshall JL, Mirra JM. Synovial chondromatosis of the thumb. A case report and review of the literature. J Bone Joint Surg. 1974;56A:180-3. 
14. Malhotra R, Gaur S, Dave PK, et al. Synovial chondromatosis of the interphalangeal joint of the thumb: a case report. J Hand Surg. 1994;19A:460-1.

15. Maurice H, Crone M, Watt I. Synovial chondromatosis. J Bone Joint Surg. 1988;70B:807-11.

16. Milgram JW. Synovial osteochondromatosis a histopathological study of thirty cases. J Bone Joint Surg Am. 1977;59A:792-801.

17. Mullins F, Berard CW, Eisenberg SH. Chondrosarcoma following synovial chondromatosis. A case study Cancer. 1965;18:1180-8.

18. Murphy FP, Dahlin DC, Sullivan CR. Articular synovial chondromatosis. J Bone Joint Surg Am. 1962;44A:77-86.

19. Nashi M, Manjunath B, Banerjee B, et al. Synovial chondromatosis in a child: an unusual cause of shoulder pain case report. J Shoulder Elbow Surg. 1998;7:642-3.

20. Ozcelik IB, Kuvat SV, Mersa B, et al. Synovial chondromatosis of the metacarpophalangeal joint of the ring finger. Acta Orthop Traumatol Turc. 2010;44(4):337-9.
21. Perry BE, McQueen DA, Lin JJ. Synovial chondromatosis with malignant degeneration to chondrosarcoma. J Bone Joint Surg Am. 1988;70A:1259-61.

22. Reed SC, Wright CS. Synovial chondromatosis of the metacarpophalangeal joint. Case report and review of the literature. Canadian J Surg. 1996;39:407-9.

23. Szepesi J. Synovial chondromatosis of the metacarpophalangeal joint. Acta Orthop Scand. 1975;46:926-30.

24. Taconis WK, Van der Heul RO, Taminiau AMM. Synovial chondrosarcoma. Report of a case and review of the literature. Skeletal Radiol. 1997;26:682-5.

25. Takami H, Takahashi S, Ando M. Synovial chondromatosis of the proximal interphalangeal joint of a finger. $\mathrm{J}$ hand Surg. 1994;19A:794-6.

26. Warme BA, Tigrani DY, Ward CM. Metacarpophalangeal joint synovial osteochondromatosis: a case report. The Iowa Orthopaedic Journal. 2000;28:91-3. 